\title{
优化教室多媒体系统 提升高中物理教学效果
}

赵建华

天津市静海区第一中学

DOI:10.32629/er.v2i9.2028

[摘 要] 应用同屏显示技术和教师个人智能手机以简单、便捷的方式融入教室多媒体系统, 构建授课移动平台, 弥补多媒体系 统自身的不足。发挥智能手机功能强大、互动性强、方便移动、资源丰富、普及率高等优势。实践研究结果表明在同屏技术 的支持下,利用教师个人智能手机构建移动平台进行授课,具有简单快捷、稳定可靠、实用性高等特点。优化多媒体辅助教学, 实现教学方式的创新,有效提高学生学习物理的兴趣和动力,对课堂教学有较大的帮助和促进作用。

[关键词] 信息化教学; 高中物理教学; 智能手机; 学习兴趣; 希沃授课助手

国家教育部颁布《教育信息化 “十三五” 规划》提出: “教育信息化工作坚持促进信息技术与教育教学深度融合 的核心理念, 积极组织推进多种形式的信息化教学活动, 鼓 励教师利用信息技术创新教学模式, 推动形成 “课堂用、经 常用、普遍用”的信息化教学新常态。”

目前, 全球已有包括美国、澳大利亚、日本、英国、新 加坡等在内的多个国家和地区开始将平板电脑作为一种新 型教学辅助工具用于课堂教学。信息化教学课件具有较大的 解释性和包容性, 强调学习的灵活性和多样性的需要, 也可 以使多媒体教学课件与教学设计的思想完美结合。因此, 教 师可以利用多媒体教学课件丰富学习资源和各种便捷的学 习, 来支持学生对内容的自主建构等。行为主义的主要观点 认为: 强调环境对个体的学习起重要作用, 学习者学到的知 识是受环境控制的, 而不是由自身因素决定的。

目前国内信息化高中课堂教学中普遍存在的教学模式 是借助多媒体平台的传统授课, 分析如下:

\section{1 教室多媒体系统现状及解决方法分析}

1. 1 教室多媒体系统存在不足和缺陷

在实际教学中, 教师只能利用电脑、投影仪、实物展台 和白板 (或银幕) 教室组成的多媒体系统播放幻灯片和音视 频课件、展示学生作业等教学活动。但也存在互动性弱, 操 作繁琐等局限性: 比如, 电脑需要鼠标操作时限制了教师的 活动范围, 不能离开讲台近距离接触并观察学生; 展示学生 的作业时, 教师奔波于学生和讲台之间, 操作投影仪时存在 聚焦难、分辨率低、取景费时等问题; 需要在白板上书写时, 亦会有强光刺眼、操作不便、身高不够等问题。诸多不便是 造成教师很少使用多媒体设施的主要原因。

1.2 移动智能终端的普及为物理课堂教学提供便利

智能手机配备多点触控屏幕使得手指代替鼠标操控电 脑更为便捷, 携带的摄像头和各种传感器等装置有效弥补了 教室多媒体系统, 网络资源和教学APP资源的应用和管理更 加便捷。智能手机超强的数据处理能力、丰富应用程序及优 越交互性能应用服务于课堂教学是必然的趋势。

教师在课堂上可以利用希沃授课助手等平台操控手机
和电脑同屏显示, 实现播放幻灯片、音视频、触屏书写、语 音录入和拍照上传等操作。教室中多媒体系统在操作方面限 制了教师的活动范围, 电脑和学生不能兼顾。使电脑便捷的 移动起来, 手机是最好的替代品。播放PPT、音视频等操作不 再被束缚在讲台, 板书书写不在受身高的限制, 投影学生作 业不必在学生和讲桌之间的空间上的制约, 演示实验不再受 看不到现象和数据的困扰。解决了教师活动受限、展示作业 费时费力、板书书写不便等问题。

\section{2 实验班和对照班成绩和教学效果分析}

2.1 光明班前测数据及结果

秩

\begin{tabular}{|c|c|c|c|c|}
\hline & 分组 & $\mathrm{N}$ & 秩均值 & 秩和 \\
\hline \multirow{3}{*}{ 光明前测成绩 } & 1.00 & 58 & 56.35 & 3268.50 \\
\hline & 2.00 & 55 & 57.68 & 3172.50 \\
\hline & 总数 & 113 & & \\
\hline
\end{tabular}

检验统计量 ${ }^{\mathrm{a}}$

\begin{tabular}{|l|r|}
\hline & \multicolumn{1}{|c|}{ 光明前测成绩 } \\
\hline Mann-Whitney U & 1557.500 \\
Wilcoxon W & 3268.500 \\
Z & -.215 \\
渐近显著性 (双侧) & .829 \\
\hline
\end{tabular}

由表可知, 两个光明班里的实验班和对照班前测显著性 $\mathrm{P}=0.892>0.05$ 水平, 之间不存在显著差异。实验班成绩平均 分虽略低于对照班, 但差距不明显。

2.2 重点班前测数据及结果

秩

\begin{tabular}{|lc|c|c|c|}
\hline & 分组 & $\mathrm{N}$ & 秩均值 & 秩和 \\
\hline 前测成绩 & 1.00 & 46 & 46.47 & 2137.50 \\
& 2.00 & 47 & 47.52 & 2233.50 \\
& 总数 & 93 & & \\
\hline
\end{tabular}

由表可知, 两个重点班里的实验班和对照班前测显著性 $\mathrm{P}=0.851>0.05$ 水平, 之间不存在显著差异。实验班成绩平均 
分略低于对照班, 但差距也不明显。

2.3 光明班后测数据及结果

Mann-Whitney 检验

\begin{tabular}{|lc|c|c|c|}
\hline 后测成绩 & 1.00 & 56 & 61.87 & 3464.50 \\
& 2.00 & 54 & 48.90 & 2640.50 \\
& 总数 & 110 & & \\
\hline
\end{tabular}

检验统计量 ${ }^{\mathrm{a}}$

\begin{tabular}{|c|c|c|c|}
\hline 组 & $\mathrm{N}$ & 秩均值 & 秩和 \\
\hline & & \multicolumn{2}{|c|}{ 光明前测成绩 } \\
\hline \multicolumn{2}{|c|}{ Mann-Whitney U } & & 1155.500 \\
\hline \multicolumn{2}{|c|}{ Wilcoxon W } & & 2640.500 \\
\hline \multicolumn{2}{|l|}{ Z } & & -.2 .132 \\
\hline \multicolumn{2}{|c|}{ 渐近显著性（双侧） } & & .033 \\
\hline
\end{tabular}

由表可知, 两个光明班里的实验班和对照班后测显著性 $\mathrm{P}=0.033<0.05$ 水平, 之间有显著差异。实验班后测成绩明显高 于对照班成绩, 差距较大。据此可以看出, 智能手机在教学中 的应用对于活泼好动、性格外向、基础较差的学生有很好的 刺激的作用, 他们乐于接受新鲜事物, 课上教师的引导, 能激 起学生相互学习, 对照自己的学习兴趣, 弥补了课下的不足, 对学习有一定的促进作用。将教师的智能手机引入高中物理 课堂这种教学模式, 对于促进学生内心学习的驱动力有利, 能 有效提高学生的学习效率, 有利于促进学生的有效学习。

2.4 重点班后测数据及结果

秩

\begin{tabular}{|c|c|c|c|c|}
\hline & 分组 & $\mathrm{N}$ & 秩均值 & 秩和 \\
\hline \multirow[t]{3}{*}{ 实验后测成绩 } & 1.00 & 49 & 50.57 & 2478.00 \\
\hline & 2.00 & 48 & 47.40 & 2275.00 \\
\hline & 总数 & 97 & & \\
\hline
\end{tabular}

检验统计量 ${ }^{a}$

\begin{tabular}{|l|r|}
\hline & \multicolumn{1}{|c|}{ 光明前测成绩 } \\
\hline Mann-Whitney U & 1099.000 \\
Wilcoxon W & 2275.000 \\
Z & -.556 \\
渐近显著性 (双侧) & .578 \\
\hline
\end{tabular}

$\mathrm{a}$ : 分组变量: 分组

由表可知, 两个重点班里的实验班和对照班后测显著性 $\mathrm{P}=0.578>0.05$ 水平, 之间没有显著差异。实验班后测成绩略 高于于对照班成绩, 实验班的平均分实现反超, 略高于对照
班。说明经过实践, 还是有些进步。由此可以看出, 智能手机 在教学中的应用对于踏实稳重、性格内向、基础较好的学生 没有太大的作用, 原因可能是学生之间的相互教和相互学的 习惯以及环境氛围已经形成, 学生能在课下的互助合作学习, 作业错误率较低, 则与课上是否利用投影批改作业关系不 大。基础知识理解到位, 学生分组实验完成良好, 无需课上进 行重点复习。

\section{3 能促进学生和教师自身的发展}

课堂被注入了新鲜元素, 定会激起了学生的好奇心, 精 神面貌也会焕然一新, 每个人也都会希望自己的作业通过老 师的手机展示给其他同学, 开始积极主动的思考问题, 尽力 完成老师布置的题目, 激起学生相互学习的兴趣和动力, 有 效提高学生的学习效率。在享受科技给他们带来的新感受的 同时, 也形成了比学赶帮超的意识, 逐渐就形成学习物理的 动机。

也能促使教师完成角色转换, 在课堂中真正起到主导作 用。同时也改变了教师的备课方式, 利用手机随时随地搜集 素材, 汶览新闻网页或是观看视频, 有针对性的有意无意的 会形成对本学科涉及的相关知识的敏感性, 无形中提高了教 师教研的意识, 延长了教师教研的时间, 有利于教师个人的 专业化发展。

综上所述, 教师和学生对多媒体的使用已经习惯, 在此 基础上将智能手机的引入课堂能对学生的学习会有更大的 促进, 学生接受手机进课堂的条件已经成熟。相反, “互联网 + ”课堂在资金、资源、意识等方面的条件并不成熟, 教师素 质和教法学法还不到位。教师需要切身的摸索, 积累经验, 而不是将来由先行者磨合出一套适应学生的信息化教学模 式, 然后教师再去学习套用。全面铺开信息化教学中的引领 者教师需要时间、需要实践、需要体会, 更需要人人参与。

\section{[参考文献]}

[1]教育部.教育信息化十年发展规划(2011-2020 年)[J]. 中国教育信息化,2012(08):3-12.

[2]于晓丽.平板电脑在高中物理课堂教学中的应用研究 [D].南京师范大学,2015(03):119.

[3]刘毓敏.多媒体课件与制作 [M]. 北京: 国防工业出版 社,2006(1):17.

[4]卢家媚.学习心理与教学[M].上海:上海教育出版社,2008:132.

[5]乔军,吴瑞华,熊才平.智能移动终端的教学应用及前 景分析[J].现代远距离教育,2013(02):81-84. 